\title{
Diagnosis and Management of Chronic Daily Headache
}

\author{
Ivan Garza, M.D., ${ }^{1}$ and Todd J. Schwedt, M.D. ${ }^{2}$
}

\section{ABSTRACT}

Chronic daily headache $(\mathrm{CDH})$ is a descriptive term that encompasses multiple headache diagnoses and affects $\sim 4 \%$ of the general adult population. Chronic daily headache results in significant pain and suffering with substantial impact on quality of life, and enormous economic costs to society. Although most patients with primary $\mathrm{CDH}$ suffer from chronic migraine or chronic tension-type headache, other primary and secondary headache disorders can also manifest as a CDH syndrome. For CDH management to succeed, secondary headaches need to be ruled out with proper investigations when judged necessary. If the diagnosis of primary $\mathrm{CDH}$ is established, diagnosis of the specific $\mathrm{CDH}$ subtype is imperative to institute appropriate treatment. The diagnosis and management of distinct $\mathrm{CDH}$ entities, chronic migraine, chronic tension-type headache, new daily persistent headache, and hemicrania continua, are the primary forms of $\mathrm{CDH}$ and the emphasis of this review. Although, strictly speaking, medication overuse headache is a secondary form of $\mathrm{CDH}$, it is also highlighted in this review given its frequent association with primary $\mathrm{CDH}$.

KEYWORDS: Chronic, daily, headache, migraine, hemicrania

Chronic daily headache $(\mathrm{CDH})$ is a descriptive term that encompasses several different headache diagnoses. Chronic daily headache affects $4 \%$ of the adult population in the United States and around the world. ${ }^{1-3}$ The vast majority of $\mathrm{CDH}$ patients suffer from either chronic migraine or chronic tension-type headache. Chronic daily headache results in significant pain and suffering, reduction in quality of life, and enormous economic costs to society. ${ }^{4,5}$

Scher has summarized the evidence from population-based studies related to risk factors influencing the incidence, prevalence, and prognosis of $\mathrm{CDH}^{6}$ Major life changes (residence change, marital status, etc.) have been associated with the onset of $\mathrm{CDH}^{7}$ Nonmodifiable factors that increase the risk for $\mathrm{CDH}$

${ }^{1}$ Department of Neurology, Mayo Clinic, Rochester, Minnesota;

${ }^{2}$ Washington University Headache Center, Washington University School of Medicine, St. Louis, Missouri.

Address for correspondence and reprint requests: Ivan Garza, M.D., Assistant Professor, Department of Neurology, Mayo Clinic, 200 First Street SW, Rochester, MN 55905 (e-mail: garza.ivan@mayo. edu). include female sex, low socioeconomic status, unmarried, history of head or neck trauma, and the presence of comorbid pain disorders. Modifiable risk factors for $\mathrm{CDH}$ include obesity, snoring and other sleep disorders, high caffeine intake, smoking, and overuse of abortive headache medications. ${ }^{6-9}$

Similar to all headache types, it is essential to exclude a secondary headache as the cause of $\mathrm{CDH}$. Depending upon the clinical history and examination findings, further diagnostic testing may or may not be necessary. Although a complete list of causes for secondary $\mathrm{CDH}$ would be exhaustive, Table 1 summarizes common considerations.

If secondary headaches are ruled out, the clinician must determine the type of primary $\mathrm{CDH}$ the patient

Headache; Guest Editor, Jerry W. Swanson, M.D., F.A.C.P.

Semin Neurol 2010;30:154-166. Copyright (C) 2010 by Thieme Medical Publishers, Inc., 333 Seventh Avenue, New York, NY 10001, USA. Tel: +1 (212) 584-4662.

DOI: http://dx.doi.org/10.1055/s-0030-1249224.

ISSN 0271-8235. 


\section{Table 1 Secondary Chronic Daily Headache}

Medication-overuse headache
Cerebrovascular disease (cerebral venous sinus thrombosis,
arteriovenous malformations, giant cell arteritis, subdural
hematoma, etc.)
Altered CSF dynamics (spontaneous CSF leak, idiopathic
intracranial hypertension, secondary intracranial
hypertension)
Intracranial space-occupying lesions (neoplasms, others)
Posttraumatic
Infection (intra- or extracranial, sinusitis)
Musculoskeletal (cervical spine disorders, temporomandibular
joint disorders)
Others

CSF, Cerebrospinal fluid.

has. Chronic migraine, chronic tension-type headache, new daily persistent headache, hemicrania continua, and medication overuse headache are discussed in this review. Although medication overuse headache is a secondary $\mathrm{CDH}$, it is included here because of the important contribution to primary $\mathrm{CDH}$.

\section{CHRONIC MIGRAINE}

Chronic migraine, which affects $\sim 2 \%$ of the world population, places a substantial burden on individuals and societies. ${ }^{10}$ Chronic migraine results in poorer quality of life and causes significant disability. ${ }^{11,12}$ The World Health Organization considers chronic migraine to cause disability on par with the disability secondary to quadriplegia, dementia, and active psychosis. ${ }^{13}$ Direct and indirect costs from migraine are estimated at more than $\$ 20$ billion annually in the United States, much of which is due to chronic migraine. ${ }^{4}$ The average annual cost per person with chronic migraine is more than four times that associated with episodic migraine ( $\$ 7750$ versus $\$ 1757){ }^{14}$

Progression from episodic migraine $(<15$ headache days/month) to chronic migraine is referred to as "transformed migraine." In population studies, 3\% of those with infrequent episodic headaches transform to $\mathrm{CDH}$ each year; $6 \%$ transform to frequent episodic headaches. ${ }^{1,15}$ In clinic-based studies, $14 \%$ of those with episodic migraine transform to chronic migraine each year. Modifiable and nonmodifiable risk factors for this transformation have been described. ${ }^{15 a}$

A detailed discussion of migraine pathophysiology is discussed in the article by Dr. Cutrer in this issue. Interictal (between migraine) and longitudinal studies of chronic migraine will hopefully lead to an improved understanding of the pathophysiology and effects of transformation from episodic migraine to chronic migraine. Elevated concentrations of vasoactive neuropeptides in the cerebrospinal fluid of chronic migraine patients suggest persistent activation of the trigeminovascular system. ${ }^{16}$ Neurogenic inflammation may lead to central sensitization, a process implicated in the chronification of migraine. Functional and structural brain changes have been identified in migraine and are positively associated with increasing headache frequency and duration. ${ }^{17}$ Chronic migraine sufferers have increased iron deposition in the periaqueductal gray, putamen, globus pallidus, and red nucleus. ${ }^{18,19}$ They have reductions in gray and white matter density and volume in multiple regions of the brain. ${ }^{20-22}$ Migraine sufferers have inferior executive function and abnormal visual motion perception even when headache free. ${ }^{23,24}$

\section{Diagnosis}

Chronic migraine patients tend to have mild to moderate headaches associated with mild migrainous features (e.g., photophobia, phonophobia) with superimposed more-severe headaches associated with more prominent migraine features ("full-blown" migraines). In some patients, environmental hypersensitivities persist even during headache-free periods. ${ }^{25}$ This may include mild photophobia, phonophobia, motion-sensitivity, and $\mathrm{cu}^{-}$ taneous hypersensitivity/allodynia. Patients with chronic migraine have an increased frequency of comorbid psychiatric disorders, sleep disorders, fatigue, other pain, and gastrointestinal complaints. Recognition and treatment of these comorbidities can result in improved health, greater quality of life, and may potentially result in higher migraine treatment success rates. The following are the recently revised diagnostic criteria for chronic migraine $^{26}$ :

1. Headache (tension-type and/or migraine) on $\geq 15$ days per month for at least 3 months

2. Occurring in a patient who has had at least five attacks fulfilling criteria for migraine without aura

3. On $\geq 8$ days per month for at least 3 months, headache has fulfilled criteria for pain and associated symptoms of migraine without aura (Criteria $\mathrm{a}$ and $\mathrm{b}$ below) or was treated and relieved by triptan(s) or ergot before the expected development of symptoms listed in Criteria a and $b$.

a. Has at least two of the following:

i. Unilateral location

ii. Pulsating quality

iii. Moderate or severe pain intensity

iv. Aggravation by or causing avoidance of routine physical activity

b. Has at least one of the following:

i. Nausea and/or vomiting

ii. Photophobia and phonophobia

4. No medication overuse and not attributed to another causative disorder 


\section{Treatment}

The treatment of chronic migraine focuses on prophylactic therapies, which may include avoidance of migraine triggers, pharmacotherapy, physical therapy, biobehavioral therapy, and others. Simultaneous use of these different therapeutic modalities may be needed. Identification and treatment of comorbid disorders is also required for true treatment success. Acute headache medication use needs to be limited to avoid medication overuse headache. Although complete headache eradication is not a realistic expectation, significant reductions in headache frequency and/or severity are the goal of prophylactic therapy.

\section{PHARMACOLOGIC PROPHYLAXIS}

Prophylactic medications used to treat episodic migraine are also used for the prevention of chronic migraine. Thus, first-line prophylactic medications are from the following classes: antidepressants, antiepileptics, and antihypertensives. The prophylactic medications that have been specifically studied in clinical trials of patients with chronic migraine are illustrated in Table 2. Once an effective prophylactic medication is found, it is typically continued for 3 to 6 months prior to attempting discontinuation. An effective prophylactic medication is one that decreases headache frequency by at least $50 \%$.

Topiramate Two randomized, double-blind, placebocontrolled studies are available. ${ }^{27,28}$ The larger of the two studies randomized 153 subjects to topiramate 100 $\mathrm{mg}$ daily and an equal number to placebo. ${ }^{27}$ Those in the topiramate group experienced a reduction of $6.4 \pm 5.8$ headache days per month from a baseline of $17.1 \pm 5.4$ days, as compared with a reduction of $4.7 \pm 6.1$ days from a baseline of $17.0 \pm 5.0$ days in the placebo group $(p=0.10)$. In the smaller of the two studies, 32 subjects were randomized to topiramate $100 \mathrm{mg}$ daily and 27 were randomized to placebo. ${ }^{28}$ Among all subjects, topiramate significantly reduced the mean number of monthly migraine days during the third month of therapy as compared with placebo $(p=0.02)$.
Gabapentin Gabapentin has been studied as a prophylactic medication for chronic daily headache in a multicenter randomized placebo-controlled crossover study of 133 subjects ( $~ 85 \%$ with migraine) ${ }^{29} \mathrm{Gaba}^{-}$ pentin $2400 \mathrm{mg}$ per day was associated with a greater percentage of headache-free days (mean 26.6\% vs. $17.5 \%, p<0.001)$ and reductions in headache duration, severity, and analgesic use.

Tizanidine Tizanidine has been studied as an adjunctive prophylactic for chronic daily headache in a multicenter, randomized, blinded, placebo-controlled study. ${ }^{30}$ One hundred thirty-six subjects $(\sim 3 / 4$ with chronic migraine) were randomized to placebo or to tizanidine titrating up from $2 \mathrm{mg}$ each night to the maximum tolerated dose, or $24 \mathrm{mg}$ divided among three daily doses. The median tizanidine dosage was $20 \mathrm{mg}$ per day. Subjects in the tizanidine group had significant reductions in headache index as compared with the placebo group.

Fluoxetine Sixty-four subjects with chronic migraine were randomized in a 16-week double-blind trial of fluoxetine. ${ }^{31,32}$ Subjects were treated with $20 \mathrm{mg}$ daily and then increased to $40 \mathrm{mg}$ daily if needed and as tolerated. Fluoxetine-treated subjects had significant improvements as compared with the placebo group in overall headache status, mood, and headache frequency.

Amitriptyline Thirty-nine transformed migraine subjects participated in a prospective double-blind study of amitriptyline versus amitriptyline plus fluoxetine. ${ }^{32}$ Although there were not significant differences in outcomes between the two treatment groups, subjects treated with amitriptyline $(8-40 \mathrm{mg} /$ day $)$ and those treated with amitriptyline plus fluoxetine $(8-20 \mathrm{mg} /$ day $)$ both had reductions in headache frequency and intensity.

Levetiracetam An open-label study of 36 transformed migraine subjects, with or without medication overuse, investigated the effect of levetiracetam. ${ }^{33}$ At 3 months,

Table 2 Prophylactic Agents Studied Specifically in Chronic Migraine

\begin{tabular}{|c|c|c|c|c|}
\hline Drug & $\begin{array}{l}\text { Initial Dose } \\
\text { (mg) }\end{array}$ & $\begin{array}{l}\text { Typical Total } \\
\text { Daily Dose (mg) }\end{array}$ & Common Side Effects & Serious Side Effects \\
\hline Topiramate & 25 & $100-200$ & Paresthesias, fatigue, weight loss & $\begin{array}{l}\text { Acute angle closure glaucoma, } \\
\text { metabolic acidosis, hyperthermia }\end{array}$ \\
\hline Gabapentin & 300 & $900-2400$ & Dizziness, somnolence, fatigue, edema & \\
\hline Tizanidine & 2 & $6-24$ & Somnolence, dry mouth, asthenia & Hepatitis \\
\hline Fluoxetine & $10-20$ & $10-80$ & Insomnia, asthenia, tremor & Prolonged QT interval \\
\hline Amitriptyline & $10-25$ & $50-150$ & Sedation, weight gain, constipation & Cardiac dysrhythmias \\
\hline Levetiracetam & 250 & $750-2000$ & Somnolence, asthenia & \\
\hline Divalproex sodium & $250-500$ & $500-1500$ & Weight gain, tremor, nausea, alopecia & $\begin{array}{l}\text { Pancreatitis, liver failure, } \\
\text { thrombocytopenia }\end{array}$ \\
\hline Memantine & 5 & $5-20$ & Dizziness & \\
\hline
\end{tabular}


levetiracetam-treated subjects had reductions in headache frequency (24.9 days/month to 16.2 days/month; $p<0.001$ ), disability (MIDAS dropped from 62.8 to $40.8 ; p=0.01$ ), and HIT-6 score (63.4 to 59.4; $p \leq 0.01)$.

Valproate Two studies suggest valproate may be useful in the prophylaxis of chronic migraine. In an open-label study of 30 patients with intractable transformed migraine, patients were maintained on dosages between 1000 to $2500 \mathrm{mg}^{34}$ A $50 \%$ or greater reduction in headache index was found in $67 \%$ of the subjects, headache-free days per month increased from 5.5 to 17.7 , and days with significant disability declined from 22 per month to 8.5 per month. The second study was a chart review of 138 chronic daily headache patients (49 with transformed migraine) being treated with divalproex sodium monotherapy. ${ }^{35}$ In the migraine patients, the mean decrease in migraine frequency was $65.2 \%$.

Botulinum Toxin Although botulinum toxin type A appears to benefit a subset of patients with chronic migraine, no consistent or strong evidence is available yet to permit drawing conclusions on its efficacy in $\mathrm{CDH}$ (mainly transformed migraine). ${ }^{36}$ Further study results are required and pending.

Memantine Memantine was recently reported to induce remission of chronic migraine. ${ }^{37}$ An open-label study further suggests this drug may play a role in chronic migraine management. ${ }^{38}$ Double-blind studies are required to establish memantine's role in chronic migraine treatment.

\section{NONPHARMACOLOGIC THERAPY}

Biofeedback, relaxation therapy, cognitive-behavioral therapy, and physical therapy may be useful as adjunctive treatments for chronic migraine. A controlled study of biofeedback showed associated decreases in oxidative stress and disability from migraine. ${ }^{39}$ Cognitive-behavioral therapy may provide short-term and long-term reductions in headache burden. ${ }^{40}$ Physical therapy is associated with significant reductions in migraine burden in some studies. ${ }^{41}$ Furthermore, a combination of physical therapy and biofeedback has been shown to provide greater relief than physical therapy alone. ${ }^{42}$

\section{Outcome}

Patients with chronic migraine may revert back to episodic migraine. Reversion rates at one year range from 56 to $70 \%$ in population-based and specialty headache clinic-based samples, respectively. ${ }^{9,43}$ Predictors of reversion include withdrawal of overused medications, compliance with prophylactic medications, and regular physical exercise.

\section{CHRONIC TENSION-TYPE HEADACHE}

Chronic tension-type headache is considerably less prevalent than episodic tension-type headache. ${ }^{44} \mathrm{~A}$ telephone survey obtained from 1993 to 1994 in Baltimore, Maryland, found an overall prevalence of $38.3 \%$ for episodic tension-type headache and a 1-year period prevalence of chronic tension-type headache of $2.2 \% .{ }^{44}$ Chronic tension-type headache increases in prevalence until the fourth decade of life and then decreases. Chronic tension-type headache is more prevalent in women compared with men and psychiatric disorders may be risk factors for its development. ${ }^{44-48}$

Although peripheral mechanisms apparently play a role in episodic tension-type headache pathophysiology, central mechanisms may play a larger role in chronic tension-type headache. ${ }^{49,50}$ Chronic tension-type headache sufferers had a general hypersensitivity to pain stimuli not seen in controls in a study of nociceptive processing. ${ }^{51}$ Central pain inhibition may be dysfunctional in chronic tension-type headache. Research using high-density electroencephalogram (EEG) brain mapping has found the supraspinal response to muscular pain to be abnormal in chronic tension-type headache sufferers. ${ }^{52}$ The reduced magnitude during and after induced tonic muscle pain in controls, but not in chronic tensiontype headache patients, might be a consequence of impaired inhibition of the nociceptive input in chronic tension-type headache. ${ }^{52}$ Deficient diffuse noxious inhibitory control-like mechanisms, such as seen in generalized chronic pain like fibromyalgia, have been found in chronic tension-type headache. ${ }^{53}$ Voxel-based morphometry and magnetic resonance imaging (MRI) have identified a significant gray matter decrease in regions involved in pain processing in chronic tensiontype headache patients. ${ }^{54}$

\section{Diagnosis}

Because it largely consists of head pain alone, tensiontype headache is frequently called "the featureless headache." ${ }^{49}$ Chronic tension-type headache typically evolves from episodic tension-type headache $\mathrm{s}^{55}$ and is usually bilateral, pressure-like in quality, and mildly to moderately intense. "Wearing a tight hat, wearing a tight band around the head, or wearing a heavy burden on the head" are frequent descriptions used by patients. ${ }^{56}$ The following are current International Classification of Headache Disorders, 2nd edition (ICHD-2) criteria for chronic tension-type headache. ${ }^{55}$

1. Headache occurring on $\geq 15$ days per month on average for $>3$ months ( $\geq 180$ days per year) and fulfilling criteria $2-4$

2. Headache lasts hours or may be continuous

3. Headache has at least two of the following characteristics: 
a. Bilateral location

b. Pressing/tightening (nonpulsating) quality

c. Mild or moderate intensity

d. Not aggravated by routine physical activity such as walking or climbing stairs

4. Both of the following:

a. No more than one of photophobia, phonophobia, or mild nausea

b. Neither moderate or severe nausea nor vomiting

5. Not attributed to another disorder

Of note, the presence of migraine attacks superimposed on a background daily "tension-type" headache could suggest that chronic migraine may be the right diagnosis rather than chronic tension-type headache. ${ }^{57}$

\section{Treatment}

Pharmacologic prophylaxis is the mainstay of treatment. Similar to chronic migraine, effective therapy is continued for at least 3 to 6 months prior to attempting discontinuation. ${ }^{58}$ Table 3 summarizes prophylactic medications studied specifically in chronic tension-type headache.

\section{PHARMACOLOGIC PROPHYLAXIS}

Amitriptyline Amitriptyline is the drug of choice, typically at doses ranging from $25 \mathrm{mg}$ to $100 \mathrm{mg}$ per day. ${ }^{50}$ This is the only antidepressant used in chronic tension-type headache that has demonstrated statistically significant benefit in several trials. ${ }^{58}$ Amitriptyline has an estimated therapeutic gain of $\sim 30 \%$ based on published trials. ${ }^{59,60}$

Nortriptyline Nortriptyline has a more favorable side effect profile than amitriptyline. ${ }^{61}$ In a randomized placebo-controlled trial, patients with chronic tensiontype headache who did not tolerate amitriptyline were switched to nortriptyline at doses of up to $75 \mathrm{mg} /$ day. $^{62}$ Both antidepressants produced larger reductions in headache, analgesic medication use, and headache-related disability than placebo. ${ }^{62}$
Protriptyline Twenty-five adult female chronic tension-type headache sufferers were studied using protriptyline $20 \mathrm{mg}$ every morning. Eighty-six percent had fewer headaches per month, and $73 \%$ had a $\geq 50 \%$ reduction in headache attacks per month. ${ }^{63}$ In contrast to the weight gain associated with other tricyclic antidepressants, patients lost slightly over three pounds during the study. ${ }^{63}$ No placebo group was used.

Mirtazapine Bendsten studied mirtazapine in a randomized, double-blind, placebo-controlled, crossover trial. Mirtazapine 15 to $30 \mathrm{mg} /$ day or placebo was given for 8 weeks separated by a 2 -week washout period. ${ }^{60}$ Mirtazapine reduced the area-under-the-headache curve by $34 \%$ more than placebo. The drug also reduced headache frequency, duration, and intensity significantly more than placebo. The efficacy of mirtazapine was similar to that of amitriptyline (a therapeutic gain of $\sim 30 \%) .{ }^{59,60}$

Topiramate In an open study, topiramate (daily dose 25 to $100 \mathrm{mg} /$ day) resulted in a $50 \%$ reduction in headache frequency in $73 \%$ of 46 chronic tension-type headache patients at weeks 13 to $24 .{ }^{64}$ Average headache intensity decreased from 6.13 to 2.07 on the visual analogue scale. ${ }^{64}$ Randomized controlled trials are needed to define topiramate's role in the management of chronic tension-type headache.

Sodium Valproate Sodium valproate $(500 \mathrm{mg}$ twice per day) was associated with greater reductions in pain frequency than placebo in 41 chronic tension-type headache subjects in a prospective, double-blind, randomized, placebo-controlled trial. ${ }^{65}$ The Visual Analog Scale pain rating did not decrease in the active group.

Tizanidine Tizanidine (6 to $18 \mathrm{mg} /$ day in divided doses) was found to be superior to placebo in a randomized, double-blind, crossover study in women with chronic tension-type headache. ${ }^{66} \mathrm{~A}$ separate randomized, double-blind, parallel-group study, however, failed to demonstrate superiority to placebo. ${ }^{67}$ To date, one

Table 3 Prophylactic Agents Studied in Chronic Tension-type Headache

\begin{tabular}{|c|c|c|c|c|}
\hline Drug & $\begin{array}{l}\text { Initial Dose } \\
\text { (mg) }\end{array}$ & $\begin{array}{l}\text { Typical Total } \\
\text { Daily Dose (mg) }\end{array}$ & Common Side Effects & Serious Side Effects \\
\hline Amitriptyline & $10-25$ & $25-100$ & Sedation, weight gain, constipation & Cardiac dysrhythmias \\
\hline Nortriptyline & $10-25$ & $25-100$ & Sedation, weight gain, constipation & Cardiac dysrhythmias \\
\hline Protriptyline & $5-10$ & $10-30$ & Sedation, weight change, constipation & Cardiac dysrhythmias \\
\hline Mirtazapine & 15 & $15-45$ & Somnolence, dry mouth & Neutropenia \\
\hline Topiramate & 25 & $100-200$ & Paresthesias, fatigue, weight loss & $\begin{array}{l}\text { Acute angle closure glaucoma, } \\
\text { metabolic acidosis, hyperthermia }\end{array}$ \\
\hline Sodium valproate & $250-500$ & $500-1000$ & Weight gain, tremor, nausea, alopecia & $\begin{array}{l}\text { Pancreatitis, liver failure, } \\
\text { thrombocytopenia }\end{array}$ \\
\hline
\end{tabular}


cannot draw firm conclusions for the potential role of tizanidine in chronic tension-type headache. ${ }^{58}$

Others Citalopram and paroxetine have not proven beneficial in chronic tension-type headache prophylaxis. ${ }^{59,68,69}$ Further research is needed to determine the potential efficacy of venlafaxine ${ }^{70}$ and buspirone. ${ }^{71}$ There is no evidence for a beneficial effect of botulinum toxin in chronic tension-type headache. ${ }^{72}$

\section{COMPLEMENTARY/ALERNATIVE TREATMENT}

In chronic tension-type headache sufferers with coexistent depression, simultaneous treatment for both disorders has shown benefit. ${ }^{73}$ Combination treatment is superior to pharmacotherapy or behavioral therapy alone. ${ }^{58}$ Combination treatment with behavioral stress management was more likely to achieve clinically significant $(\geq 50 \%)$ reductions in headache index scores (64\% of participants) than antidepressant medication (38\% of participants), stress management therapy $(35 \%)$, or placebo $(29 \%)$ in a randomized placebo-controlled trial of 203 chronic tension-type headache subjects. ${ }^{62}$

The potential role of acupuncture in chronic tension-type headache is yet to be defined. In one study, relaxation training induced the best benefit compared with acupuncture and physical training. ${ }^{74}$ The potential role of hypnosis ${ }^{75}$ and structured massage ${ }^{76}$ remain to be determined. Other noninvasive physical treatments with some evidence in chronic tension-type headache prophylaxis include spinal manipulation, cranial electrotherapy, transcutaneous electrical nerve stimulation (TENS)/electrical neurotransmitter modulation combination, and automassage/TENS/stretching combination. $^{77}$

\section{ACUTE PHARMACOLOGIC THERAPY}

Simple analgesics and nonsteroidal antiinflammatory drugs (NSAIDs) remain as the pillar of abortive treatment in tension-type headache. ${ }^{50}$ Acetaminophen/isometheptene/ dichloralphenazone frequently helps more severe episodes not responding to NSAIDs.

\section{MEDICATION-OVERUSE HEADACHE}

Medication-overuse headache frequently coexists with primary $\mathrm{CDH}$ and can preclude effective therapy of the latter. In some cases medication overuse headache may be responsible for the development or maintenance of a $\mathrm{CDH}$ syndrome ${ }^{78}$; in other cases, medication overuse is the result of frequent headaches. Prophylactic medications for primary $\mathrm{CDH}$ are more likely to provide benefit following successful medication-overuse headache management. $^{79}$

The prevalence of medication-overuse headache in the general population is $\sim 1.5 \%{ }^{80}$ The female to male ratio is $3.5: 1 .^{81}$ In tertiary headache clinics throughout America, up to 50 to $80 \%$ of patients have medication-overuse headache. ${ }^{80} \mathrm{By}$ far, migraine is the most common primary headache disorder associated with medication-overuse headache. In a meta-analysis summarizing 29 studies, $65 \%$ of 2612 patients with chronic medication overuse headache had migraine, $27 \%$ had tension-type, and $8 \%$ had mixed or other type of primary headache. ${ }^{81}$

The risk for medication overuse headache development differs with individual substances. Opioids, butalbital-containing analgesics, and aspirin/acetaminophen/caffeine combinations are high risk; triptans are moderate risk; and NSAIDs are low risk. ${ }^{82}$ In a recent longitudinal population-based study, any use of barbiturates and opiates was associated with increased risk of transformed migraine. ${ }^{83}$ Critical dose of opiate exposure was around 8 days per month, and the effect was more pronounced in men. ${ }^{84}$ Critical dose of barbiturate exposure was around 5 days per month and the effect was more pronounced in women. ${ }^{84}$ Triptans and NSAIDs induced migraine progression in those with high frequency of migraine at baseline (10-14 days per month), but not overall. ${ }^{84}$

Multiple mechanisms may be involved in the development of medication-overuse headache. ${ }^{85}$ Development of medication-overuse headache appears to be restricted to those with underlying headache disorders as it does not develop de novo in those without headaches who overuse the same medications. ${ }^{85,86}$ Neurophysiologic studies have shown facilitation of trigeminal and somatic nociceptive systems in medication-overuse headache, mainly mediated at a supraspinal level. ${ }^{87}$ This suggests central sensitization (a process also involved in migraine pathophysiology) may also be involved in medication-overuse headache pathophysiology. Studies using 18-fluorodeoxyglucose positron emission tomography (18-FDG PET) have identified reversible metabolic changes in pain processing structures and persistent orbitofrontal hypofunction in migraine patients with coexistent medication overuse headache. ${ }^{88}$ Chronic morphine exposure results in increased descending facilitation from the rostral ${ }^{88}$ ventromedial medulla and increased excitatory neurotransmission at the dorsal horn. ${ }^{89}$ Sometimes, substance addiction may be the base for medication overuse headache. Others appear to be treating pain and a comorbid anxiety disorder with the same medication (e.g., opiates). ${ }^{90}$ Out of 895 patients with medication overuse headache studied in a prospective fashion, $68 \%$ met three of five substance-dependence criteria according to the Diagnostic and Statistical Manual of Mental Disorders, Fourth Edition (DSM-IV) versus 20\% in those without medication-overuse headache. ${ }^{91}$ Fear of headache, anticipatory anxiety, obsessive drug-taking behaviors, and psychological drug dependence may also help induce and then sustain medication-overuse headache. ${ }^{90}$ 


\section{Diagnosis}

As discussed earlier, medication-overuse headache patients typically have a primary headache disorder that increased in frequency and led to increased analgesic consumption and then medication-overuse headache. It is not uncommon for patients to take frequent analgesics solely to prevent a severe analgesic-withdrawal headache. ${ }^{85}$ Medication overuse headache varies in its characteristics (severity, location, type) and is frequently associated with nausea, asthenia, and cognitive difficulties (impaired memory, poor concentration, irritability). ${ }^{80}$ If a $\mathrm{CDH}$ sufferer is taking analgesics more than 2 to 3 days per week on average, medication-overuse headache should always be suspected. The following are current ICHD-2 diagnostic criteria for medication overuse headache. Please note that the type of medication overused is important for proper diagnosis. ${ }^{80}$

1. Headache present on $\geq 15$ days/month

2. Regular overuse for $>3$ months of one or more acute/ symptomatic treatment drugs

a. Ergotamine, triptans, opioids, or combination analgesic medications on $\geq 10$ days/month on a regular basis for $>3$ months

b. Simple analgesics or any combination of ergotamine, triptans, analgesic opioids on $\geq 15$ days/ month on a regular basis for $>3$ months without overuse of any single class alone

3. Headache has developed or markedly worsened during medication overuse

\section{Treatment}

Abrupt drug withdrawal remains the treatment of choice when dangerous physical withdrawal is not a concern. ${ }^{85}$ Proper management of medication-overuse headache should include the following steps:

1. Patient education

2. Withdrawal of offending medication

3. "Bridging" aimed at symptomatic relief during medication withdrawal

4. Establish new acute and preventive headache treatment regimen

5. Follow-up and headache reassessment

6. Relapse prevention

\section{Patient Education}

Patients with medication-overuse headache need to understand that as long as they are overusing analgesics, headache preventives may be less effective or not effective at all. ${ }^{79,89}$ They need to be educated on why analgesic overuse is detrimental. The majority of medication-overuse headache patients benefit from drug withdrawal. Benefit may be from the withdrawal alone or from a "reparative" change from treatment failure to favorable response to medical management. ${ }^{79,92}$

\section{Withdrawal of the Offending Medication}

During analgesic withdrawal, headaches frequently exacerbate before starting to improve. ${ }^{89}$ Nausea, vomiting, restlessness, anxiety, and sleep disturbances may also occur during withdrawal. ${ }^{85,89}$ Withdrawal symptoms usually last 2 to 10 days (mean 3.5 days), ${ }^{85}$ but can endure for 2 to 4 weeks. ${ }^{89}$ Although many physicians prefer inpatient programs for withdrawal, ${ }^{85}$ most patients can be managed on an outpatient basis. ${ }^{89} \mathrm{~A}$ recent prospective, randomized trial in patients with migraine and superimposed medication-overuse headache showed that simple, strong advice was as effective as structured inpatient and outpatient detoxification programs in achieving medication withdrawal. ${ }^{93}$ The mean success rate of withdrawal treatment at 1 to 6 months was $72.4 \%$ in a meta-analysis. ${ }^{85}$

\section{Bridging}

The goal of "bridging" is to provide symptomatic relief during acute medication withdrawal. No clear guidelines or consensus recommendations exist. ${ }^{94}$ Bridging recommendations are based on case series, retrospective chart reviews, prospective uncontrolled studies, and expert opinion. ${ }^{89}$ Some studies support the use of corticosteroids; others do not. ${ }^{95}$ Further randomized, placebo-controlled trials are needed to clarify the potential role of corticosteroids in medication-overuse headache management. ${ }^{96}$ Antiemetics are often prescribed in addition to the following published strategies.

\section{ORAL}

Naproxen $500 \mathrm{mg}$ twice a day until withdrawal is complete $^{97}$

Naproxen sodium $550 \mathrm{mg}$ twice a day for 2 to 4 weeks $^{89}$

Naproxen sodium $550 \mathrm{mg}$ twice a day for 1 week, then once a day for 1 week $^{89}$

Prednisone $60 \mathrm{mg} /$ day, decrease by $20 \mathrm{mg}$ every 2 days $\left(\right.$ total 6 days) ${ }^{98}$

Prednisone $100 \mathrm{mg}$ for 5 days ${ }^{96}$

\section{INJECTED}

Intravenous (IV) methylprednisolone 100 to $200 \mathrm{mg}$ every 12 hours for 2 to 3 days 89,99

IV or intramuscular (IM) dexamethasone 8 to $20 \mathrm{mg} /$ day, tapering over 2 to 3 days $^{98}$

IV hydrocortisone $100 \mathrm{mg}$ every 6 hours for 24 hours; every 8 hours for 24 hours; then every 12 hours for 24 hours $^{98}$

Repetitive IV dihydroergotamine (DHE; inpatient): IV metoclopramide $10 \mathrm{mg}$, followed by $0.5 \mathrm{mg}$ IV DHE. 
Doses adjusted based on headache severity and side effects ${ }^{100}$

Continuous IV DHE (inpatient): $3 \mathrm{mg}$ of DHE in $1000 \mathrm{~mL}$ of normal saline at $42 \mathrm{~mL} / \mathrm{h}$ by IV infusion pump, totaling $3 \mathrm{mg}$ of DHE administered at constant rate over 24 hours ${ }^{101}$

Subcutaneous DHE (outpatient): $1 \mathrm{mg}$ twice a day for 1 week followed by $0.5 \mathrm{mg}$ twice a day for 1 week, or $1 \mathrm{mg}$ twice a day for 1 week followed by $1 \mathrm{mg}$ every day for 1 week $^{89}$

IV valproate sodium: loading dose of $15 \mathrm{mg} / \mathrm{kg}$ followed by daily maintenance of $5 \mathrm{mg} / \mathrm{kg}$ every 8 hours for 12 to 48 hours $^{102}$

IV prochlorperazine starting with $5 \mathrm{mg}$ to $10 \mathrm{mg}$ every 8 hours, with dosage adjustment according to efficacy and side effects until headache-free ${ }^{99}$

\section{Establish Appropriate Headache Prevention}

Whether pharmacologic prophylaxis should be started at the time of medication withdrawal remains an ongoing dispute. ${ }^{103}$ Because most patients will require long-term preventives, the authors recommend starting such treatment at the time of withdrawal. Preventives are chosen according to the type of underlying primary headache disorder.

\section{Follow-up and Headache Reassessment}

Once the overused medications have been withdrawn, patients frequently return to a pattern of intermittent headaches. These headaches need to be classified and treated accordingly.

\section{Relapse Prevention}

Most relapses occur in the first year following withdrawal. ${ }^{104}$ In general, avoidance of opiates and/ or butalbital for the regular management of primary headache disorders is recommended. Limitations for the frequency of analgesic intake should be explained: triptan or combination analgesic use should be limited to 9 or fewer days a month on average and NSAIDs to 15 or fewer days a month to prevent medication-overuse headache relapse. ${ }^{105}$ The identification and management of comorbidities (anxiety, etc.) that may contribute to medication overuse headache development and preservation are of paramount importance to prevent medication overuse headache relapse. $^{90}$

\section{NEW DAILY PERSISTENT HEADACHE}

New daily persistent headache, one of the most treatment refractory headaches, is a headache that begins one day and typically does not remit. ${ }^{106} \mathrm{New}$ daily persistent headache affects women more than men with reported ratios of 1.3:1 and 2.5:1.0 and can essentially affect all age groups. ${ }^{107-109}$ Peak age of onset is in the second and third decades for women and the fifth decade in men. ${ }^{109}$ Overall mean age of onset is 35 years of age. ${ }^{108}$ Although new daily persistent headache is estimated to occur infrequently in the general population, the exact frequency is unknown. ${ }^{108}$ In headache clinics, however, $\sim 1$ in $10 \mathrm{CDH}$ patients have new daily persistent headache. ${ }^{110}$

The etiology of new daily persistent headache is not well understood. Although the nature of the associations is unclear, infection, flu-like illness, surgery, and stressful life events may precede new daily persistent headache. ${ }^{109}$ How these may result in new daily persistent headache is unknown and in many patients, no precipitating factors exist. ${ }^{108}$ Possible associations between new daily persistent headache and Epstein-Barr virus (EBV), herpes simplex virus (HSV), and cytomegalovirus (CMV) have been suggested but remain unproven. ${ }^{109,111-114}$

\section{Diagnosis}

The vast majority of patients (up to $82 \%$ ) can vividly recall the exact date the headache started. ${ }^{109}$ In most, $\sim 80 \%$, the pain is continuous. ${ }^{108,109}$ Pain intensity tends to be moderate, although many patients experience severe pain. ${ }^{109}$ Clinical features vary significantly. Headaches may have primarily migraine features (photophobia, nausea, etc.) or be "featureless" and reminiscent of chronic tension-type headache. ${ }^{107-109}$ Secondary headache disorders, including those due to spontaneous cerebrospinal (CSF) leaks and cerebral venous sinus thrombosis, need to be ruled out. ${ }^{55,106} \mathrm{MRI}$ of the brain with gadolinium and magnetic resonance venography (MRV) should be considered. Clinical judgment guides further investigations, if any. Current ICHD-2 diagnostic criteria for new daily persistent headache are as follows: ${ }^{55}$

1. Headache for $>3$ months fulfilling Criteria 2 through 4

2. Headache is daily and unremitting from onset or from $<3$ days from onset

3. At least two of the following pain characteristics:
a. Bilateral location
b. Pressing/tightening (nonpulsating) quality
c. Mild or moderate intensity

4. Not aggravated by routine physical activity, such as walking or climbing stairs

5. Both of the following:
a. No more than one of photophobia, phonophobia, or mild nausea
b. Neither moderate or severe nausea nor vomiting

6. Not attributed to another disorder 
Of note, although the above criteria reflect essentially a chronic tension-type headache phenotype, migrainous features are frequently reported. ${ }^{115}$ Diagnostic criteria will likely be modified as knowledge about this disorder expands.

\section{Treatment}

New daily persistent headache can endure for many years (even decades) and can be disabling. Despite proper treatment, the headache frequently does not abate. ${ }^{106}$ Takase found treatment to be very effective in $27 \%$, moderately effective in $3 \%$, mildly effective in $20 \%$, and not effective in $50 \%$ of 30 new daily persistent headache sufferers. ${ }^{108}$ In agreement with other headache specialists, ${ }^{116}$ we recommend classifying the dominant headache phenotype, whether it is migraine or tension-type, and treat with preventives accordingly.

New daily persistent headache has been reported to take one of the following courses: a self-limited one typically resolving without treatment within several months, or a refractory course resistant to aggressive treatment. ${ }^{55}$ Although most patients are headache free at 2 years in some series, in others (and in practice) new daily persistent headache may be refractory to treatment for many years. ${ }^{106-109,113}$

\section{HEMICRANIA CONTINUA}

Hemicrania continua is a one-sided continuous headache of moderate severity with superimposed severe exacerbations of pain often associated with ipsilateral autonomic symptoms. The frequency of hemicrania continua in the general population is unknown. ${ }^{117}$ Hemicrania continua may begin at any age, but peaks in the third decade of life. ${ }^{118}$ It is twice as common in women than men. ${ }^{119}$

The pathophysiology of hemicrania continua is incompletely understood. However, a PET study of seven patients with hemicrania continua showed significant activation of the contralateral posterior hypothalamus and ipsilateral rostral pons during baseline pain that were blocked by administration of indomethacin. ${ }^{120}$ PET in one patient with hemicrania continua without autonomic features, who had dorsal pontine activation but no hypothalamic activation, suggests that the hypothalamus may play a role in autonomic activation, perhaps via disinhibition of the trigeminal-autonomic reflex. ${ }^{121}$

\section{Diagnosis}

Hemicrania continua is a unilateral headache that is continuous in nature. Continuous pain is generally moderate in intensity. There are superimposed severe attacks of pain that last minutes to several days classically associated with autonomic features (lacrimation, miosis, etc.). ${ }^{122}$ Although not fulfilling the diagnostic criteria, ${ }^{55}$ a subgroup of patients with continuous one-sided headaches completely responsive to indomethacin do not have autonomic symptoms. ${ }^{123}$ Mild migrainous features may be present, and some patients develop superimposed headaches consistent with migraine headaches. ${ }^{124} \mathrm{Ipsi}-$ lateral ocular discomfort or an ocular foreign body sensation and a superimposed stabbing headache ("jabs and jolts") are often reported. ${ }^{118}$ ICHD-2 diagnostic criteria are as follows: ${ }^{55}$

1. Headache for $>3$ months fulfilling Criteria 2 through 4

2. All of the following characteristics:

a. Unilateral pain without side-shift

b. Daily and continuous, without pain-free periods

c. Moderate intensity, but with exacerbations of severe pain

3. At least one of the following autonomic features occurs during exacerbations and ipsilateral to the side of pain:

a. Conjunctival injection and/or lacrimation

b. Nasal congestion and/or rhinorrhea

c. Ptosis and/or miosis

4. Complete response to therapeutic doses of indomethacin

5. Not attributed to another disorder

Secondary headaches mimicking primary hemicrania continua (including response to indomethacin) have been reported, including internal carotid artery dissection, unruptured aneurysm, pineal cyst, pituitary tumor, ipsilateral mesenchymal tumor of the sphenoidal bone involving the clinoid process at the base of the skull, lung adenocarcinoma, and pontine stroke. ${ }^{125-130}$ Diagnostic studies must therefore be ordered as necessary.

If hemicrania continua is suspected, an oral indomethacin test can be used for the diagnosis of hemicrania continua. One of several methods is as follows: $50 \mathrm{mg}$ twice per day for 3 days, $50 \mathrm{mg}$ three times per day for 3 days, $50 \mathrm{mg}$ four times per day for 3 days. Indomethacin response is typically fast. In a prospective study of 12 hemicrania continua patients, complete pain relief was obtained within 48 hours in all cases, within 24 hours in 10 of the patients, and within 8 hours in nine. ${ }^{131}$ Completion of the test without headache resolution is considered a failed trial.

\section{Treatment}

Due to absolute response to indomethacin, it is the treatment of choice for hemicrania continua. The appropriate dose will vary among patients. The initial dose is that dose which results in resolution of headache, determined during the diagnostic indomethacin trial. Oral doses ranging from $25 \mathrm{mg}$ to $300 \mathrm{mg}$ per day 
have been reported effective. However, given adverse side effects of indomethacin, the lowest effective dose is the desired dose. Periodic attempts to decrease the dose should be made. Potential side effects from indomethacin are numerous. Administration of indomethacin with food can reduce gastrointestinal side effects. Treatment with gastric mucosal protectants, such as proton-pump inhibitors, may also decrease this risk and is common practice. Many of these potential side effects are doserelated. Approximately one of three patients report side effects attributable to indomethacin therapy. ${ }^{132}$ Contraindications to treatment with indomethacin and/or discontinuation due to intolerance have led to the search for alternative therapies. There have been case reports of efficacy with melatonin, topiramate, verapamil, cox-2 inhibitors, gabapentin, botulinum toxin type A, and occipital nerve stimulation. ${ }^{119,133-138}$

\section{REFERENCES}

1. Scher AI, Stewart WF, Liberman J, Lipton RB. Prevalence of frequent headache in a population sample. Headache 1998;38(7):497-506

2. Lu SR, Fuh JL, Chen WT, Juang KD, Wang SJ. Chronic daily headache in Taipei, Taiwan: prevalence, follow-up and outcome predictors. Cephalalgia 2001;21(10):980-986

3. Wang SJ, Fuh JL, Lu SR, et al. Chronic daily headache in Chinese elderly: prevalence, risk factors, and biannual follow-up. Neurology 2000;54(2):314-319

4. Stewart WF, Ricci JA, Chee E, Morganstein D, Lipton R. Lost productive time and cost due to common pain conditions in the US workforce. JAMA 2003;290(18):2443-2454

5. Lipton RB, Stewart WF, Scher AI. Epidemiology and economic impact of migraine. Curr Med Res Opin 2001;17 (Suppl 1):s4-s12

6. Scher AI, Midgette LA, Lipton RB. Risk factors for headache chronification. Headache 2008;48(1):16-25

7. Scher AI, Stewart WF, Buse D, Krantz DS, Lipton RB. Major life changes before and after the onset of chronic daily headache: a population-based study. Cephalalgia 2008;28 (8):868-876

8. Scher AI, Stewart WF, Lipton RB. Caffeine as a risk factor for chronic daily headache: a population-based study. Neurology 2004;63(11):2022-2027

9. Scher AI, Stewart WF, Ricci JA, Lipton RB. Factors associated with the onset and remission of chronic daily headache in a population-based study. Pain 2003;106(1-2): 81-89

10. Castillo J, Muñoz P, Guitera V, Pascual J. Kaplan Award 1998. Epidemiology of chronic daily headache in the general population. Headache 1999;39(3):190-196

11. Guitera V, Muñoz P, Castillo J, Pascual J. Quality of life in chronic daily headache: a study in a general population. Neurology 2002;58(7):1062-1065

12. D'Amico D, Usai S, Grazzi L, et al. Quality of life and disability in primary chronic daily headaches. Neurol Sci 2003;24(Suppl 2):S97-S100

13. Harwood RH, Sayer AA, Hirschfeld M. Current and future worldwide prevalence of dependency, its relationship to total population, and dependency ratios. Bull World Health Organ 2004;82(4):251-258

14. Munakata J, Hazard E, Serrano D, et al. Economic burden of transformed migraine: results from the American Migraine Prevalence and Prevention (AMPP) Study. Headache 2009;49(4):498-508

15. Katsarava Z, Schneeweiss S, Kurth $\mathrm{T}$, et al. Incidence and predictors for chronicity of headache in patients with episodic migraine. Neurology 2004;62(5):788-790

15a. Lipton RB. Tracing transformation: chronic migration classification, progression, and epidemiology. Neurology 2009;72(5 Suppl):S3-S7

16. Sarchielli P, Alberti A, Floridi A, Gallai V. Levels of nerve growth factor in cerebrospinal fluid of chronic daily headache patients. Neurology 2001;57(1):132-134

17. Schwedt TJ, Dodick DW. Advanced neuroimaging of migraine. Lancet Neurol 2009;8(6):560-568

18. Welch KM, Nagesh V, Aurora SK, Gelman N. Periaqueductal gray matter dysfunction in migraine: cause or the burden of illness? Headache 2001;41(7):629-637

19. Kruit MC, Launer LJ, Overbosch J, van Buchem MA, Ferrari MD. Iron accumulation in deep brain nuclei in migraine: a population-based magnetic resonance imaging study. Cephalalgia 2009;29(3):351-359

20. Schmitz N, Admiraal-Behloul F, Arkink EB, et al. Attack frequency and disease duration as indicators for brain damage in migraine. Headache 2008;48(7):1044-1055

21. Valfrè W, Rainero I, Bergui M, Pinessi L. Voxel-based morphometry reveals gray matter abnormalities in migraine. Headache 2008;48(1):109-117

22. Rocca MA, Ceccarelli A, Falini A, et al. Brain gray matter changes in migraine patients with T2-visible lesions: a 3-T MRI study. Stroke 2006;37(7):1765-1770

23. Schmitz N, Arkink EB, Mulder M, et al. Frontal lobe structure and executive function in migraine patients. Neurosci Lett 2008;440(2):92-96

24. Granziera C, DaSilva AF, Snyder J, Tuch DS, Hadjikhani $\mathrm{N}$. Anatomical alterations of the visual motion processing network in migraine with and without aura. PLoS Med 2006;3(10):e402

25. Ashkenazi A, Mushtaq A, Yang I, Oshinsky ML. Ictal and interictal phonophobia in migraine-a quantitative controlled study. Cephalalgia 2009;29(10):1042-1048

26. Olesen J, Bousser MG, Diener HC, et al; Headache Classification Committee. New appendix criteria open for a broader concept of chronic migraine. Cephalalgia 2006; 26(6):742-746

27. Silberstein SD, Lipton RB, Dodick DW, et al; Topiramate Chronic Migraine Study Group. Efficacy and safety of topiramate for the treatment of chronic migraine: a randomized, double-blind, placebo-controlled trial. Headache 2007;47(2):170-180

28. Diener HC, Bussone $G$, Van Oene JC, Lahaye $M$, Schwalen S, Goadsby PJ; TOPMAT-MIG-201(TOPCHROME) Study Group. Topiramate reduces headache days in chronic migraine: a randomized, double-blind, placebo-controlled study. Cephalalgia 2007;27(7):814-823

29. Spira PJ, Beran R; GAustralian Gabapentin Chronic Daily Headache Group. Gabapentin in the prophylaxis of chronic daily headache: a randomized, placebo-controlled study. Neurology 2003;61(12):1753-1759

30. Saper JR, Lake AE III, Cantrell DT, Winner PK, White JR. Chronic daily headache prophylaxis with tizanidine: 
a double-blind, placebo-controlled, multicenter outcome study. Headache 2002;42(6):470-482

31. Saper JR, Silberstein SD, Lake AE III, Winters ME. Double-blind trial of fluoxetine: chronic daily headache and migraine. Headache 1994;34(9):497-502

32. Krymchantowski AV, Silva MT, Barbosa JS, Alves LA. Amitriptyline versus amitriptyline combined with fluoxetine in the preventative treatment of transformed migraine: a double-blind study. Headache 2002;42(6):510-514

33. Rapoport AM, Sheftell FD, Tepper SJ, Bigal M. Levetiracetam in the preventive treatment of transformed migraine. Curr Ther Res 2005;66:212-221

34. Mathew NT, Ali S. Valproate in the treatment of persistent chronic daily headache. An open label study. Headache 1991; 31(2):71-74

35. Freitag FG, Diamond S, Diamond ML, Urban GJ. Divalproex in the long-term treatment of chronic daily headache. Headache 2001;41(3):271-278

36. Naumann M, So Y, Argoff CE, et al; Therapeutics and Technology Assessment Subcommittee of the American Academy of Neurology. Assessment: Botulinum neurotoxin in the treatment of autonomic disorders and pain (an evidence-based review): report of the Therapeutics and Technology Assessment Subcommittee of the American Academy of Neurology. Neurology 2008;70(19):1707-1714

37. Spengos K, Theleritis C, Paparrigopoulos T. Memantine and NMDA antagonism for chronic migraine: a potentially novel therapeutic approach? Headache 2008;48(2):284-286

38. Bigal M, Rapoport A, Sheftell F, Tepper D, Tepper S. Memantine in the preventive treatment of refractory migraine. Headache 2008;48(9):1337-1342

39. Ciancarelli I, Tozzi-Ciancarelli MG, Spacca G, Di Massimo C, Carolei A. Relationship between biofeedback and oxidative stress in patients with chronic migraine. Cephalalgia 2007;27(10):1136-1141

40. Martin PR, Forsyth MR, Reece J. Cognitive-behavioral therapy versus temporal pulse amplitude biofeedback training for recurrent headache. Behav Ther 2007;38(4):350-363

41. Lockett DM, Campbell JF. The effects of aerobic exercise on migraine. Headache 1992;32(1):50-54

42. Marcus DA, Scharff L, Mercer S, Turk DC. Nonpharmacological treatment for migraine: incremental utility of physical therapy with relaxation and thermal biofeedback. Cephalalgia 1998;18(5):266-272, discussion 242

43. Seok JI, Cho HI, Chung CS. From transformed migraine to episodic migraine: reversion factors. Headache 2006;46(7): $1186-1190$

44. Schwartz BS, Stewart WF, Simon D, Lipton RB. Epidemiology of tension-type headache. JAMA 1998; 279(5):381-383

45. Lavados PM, Tenhamm E. Epidemiology of tension-type headache in Santiago, Chile: a prevalence study. Cephalalgia 1998;18(8):552-558

46. Russell MB, Levi N, Saltyte-Benth J, Fenger K. Tensiontype headache in adolescents and adults: a population based study of 33,764 twins. Eur J Epidemiol 2006;21(2):153160

47. Bendtsen L, Jensen R. Tension-type headache: the most common, but also the most neglected, headache disorder. Curr Opin Neurol 2006;19(3):305-309

48. Juang KD, Wang SJ, Fuh JL, Lu SR, Su TP. Comorbidity of depressive and anxiety disorders in chronic daily headache and its subtypes. Headache 2000;40(10):818-823
49. Fumal AS. Chronic tension-type headache. In: Goadsby PJ, Dodick DW, eds. Chronic Daily Headache for Clinicians. 1st Ed. Hamilton, Ontario: BC Decker Inc; 2005:57-64

50. Mathew NT. Tension-type headache. Curr Neurol Neurosci Rep 2006;6(2):100-105

51. Bendtsen L, Jensen R, Olesen J. Decreased pain detection and tolerance thresholds in chronic tension-type headache. Arch Neurol 1996;53(4):373-376

52. Buchgreitz L, Egsgaard LL, Jensen R, Arendt-Nielsen L, Bendtsen L. Abnormal pain processing in chronic tensiontype headache: a high-density EEG brain mapping study. Brain 2008;131(Pt 12):3232-3238

53. Pielsticker A, Haag G, Zaudig M, Lautenbacher S. Impairment of pain inhibition in chronic tension-type headache. Pain 2005;118(1-2):215-223

54. Schmidt-Wilcke T, Leinisch E, Straube A, et al. Gray matter decrease in patients with chronic tension type headache. Neurology 2005;65(9):1483-1486

55. Headache Classification Subcommittee of the International Headache Society. The International Classification of Headache Disorders, 2nd Edition. Cephalalgia 2004; 24(Suppl 1):1-160

56. Jensen R, Becker WJ. Symptomatology of chronic tensiontype headaches. In: Olesen J, Ramadan NM, Tfelt-Hansen P, Welch KMA, eds. The Headaches. 3rd ed. Philadelphia: Lippincott Williams and Wilkins; 2006:693-699

57. Bigal ME, Lipton RB. Tension-type headache: classification and diagnosis. Curr Pain Headache Rep 2005;9(6): 423-429

58. Lenaerts ME. Pharmacoprophylaxis of tension-type headache. Curr Pain Headache Rep 2005;9(6):442-447

59. Bendtsen L, Jensen R, Olesen J. A non-selective (amitriptyline), but not a selective (citalopram), serotonin reuptake inhibitor is effective in the prophylactic treatment of chronic tension-type headache. J Neurol Neurosurg Psychiatry 1996; 61(3):285-290

60. Bendtsen L, Jensen R. Mirtazapine is effective in the prophylactic treatment of chronic tension-type headache. Neurology 2004;62(10):1706-1711

61. Garza I, Swanson JW. Prophylaxis of migraine. Neuropsychiatr Dis Treat 2006;2(3):281-291

62. Holroyd KA, O'Donnell FJ, Stensland M, Lipchik GL, Cordingley GE, Carlson BW. Management of chronic tension-type headache with tricyclic antidepressant medication, stress management therapy, and their combination: a randomized controlled trial. JAMA 2001;285(17):22082215

63. Cohen GL. Protriptyline, chronic tension-type headaches, and weight loss in women. Headache 1997;37(7):433-436

64. Lampl C, Marecek S, May A, Bendtsen L. A prospective, open-label, long-term study of the efficacy and tolerability of topiramate in the prophylaxis of chronic tension-type headache. Cephalalgia 2006;26(10):1203-1208

65. Yurekli VA, Akhan G, Kutluhan S, Uzar E, Koyuncuoglu HR, Gultekin F. The effect of sodium valproate on chronic daily headache and its subgroups. J Headache Pain 2008; 9(1):37-41

66. Fogelholm R, Murros K. Tizanidine in chronic tension-type headache: a placebo controlled double-blind cross-over study. Headache 1992;32(10):509-513

67. Murros K, Kataja M, Hedman C, et al. Modified-release formulation of tizanidine in chronic tension-type headache. Headache 2000;40(8):633-637 
68. Langemark M, Olesen J. Sulpiride and paroxetine in the treatment of chronic tension-type headache. An explanatory double-blind trial. Headache 1994;34(1):20-24

69. Holroyd KA, Labus JS, O’Donnell FJ, Cordingley GE. Treating chronic tension-type headache not responding to amitriptyline hydrochloride with paroxetine hydrochloride: a pilot evaluation. Headache 2003;43(9):999-1004

70. Adelman LC, Adelman JU, Von Seggern R, Mannix LK. Venlafaxine extended release (XR) for the prophylaxis of migraine and tension-type headache: A retrospective study in a clinical setting. Headache 2000;40(7):572-580

71. Mitsikostas DD, Gatzonis S, Thomas A, Ilias A. Buspirone vs amitriptyline in the treatment of chronic tension-type headache. Acta Neurol Scand 1997;96(4):247-251

72. Schulte-Mattler WJ, Martinez-Castrillo JC. Botulinum toxin therapy of migraine and tension-type headache: comparing different botulinum toxin preparations. Eur J Neurol 2006; 13(Suppl 1):51-54

73. Walker Z, Walker RW, Robertson MM, Stansfeld S. Antidepressant treatment of chronic tension-type headache: a comparison between fluoxetine and desipramine. Headache 1998;38(7):523-528

74. Söderberg E, Carlsson J, Stener-Victorin E. Chronic tension-type headache treated with acupuncture, physical training and relaxation training. Between-group differences. Cephalalgia 2006;26(11):1320-1329

75. Melis PM, Rooimans W, Spierings EL, Hoogduin CA. Treatment of chronic tension-type headache with hypnotherapy: a single-blind time controlled study. Headache 1991;31(10):686-689

76. Quinn C, Chandler C, Moraska A. Massage therapy and frequency of chronic tension headaches. Am J Public Health 2002;92(10):1657-1661

77. Bronfort G, Nilsson N, Haas M, et al. Non-invasive physical treatments for chronic/recurrent headache. Cochrane Database Syst Rev 2004;(3):CD001878

78. Bigal ME, Rapoport AM, Sheftell FD, Tepper SJ, Lipton RB. Transformed migraine and medication overuse in a tertiary headache centre-clinical characteristics and treatment outcomes. Cephalalgia 2004;24(6):483-490

79. Mathew NT, Kurman R, Perez F. Drug induced refractory headache-clinical features and management. Headache 1990;30(10):634-638

80. Dodick D, Freitag F. Evidence-based understanding of medication-overuse headache: clinical implications. Headache 2006;46(Suppl 4):S202-S211

81. Kavuk I, Katsarava Z, Selekler M, et al. Clinical features and therapy of medication overuse headache. Eur J Med Res 2004;9(12):565-569

82. Smith TR, Stoneman J. Medication overuse headache from antimigraine therapy: clinical features, pathogenesis and management. Drugs 2004;64(22):2503-2514

83. Bigal ME, Serrano D, Buse D, Scher A, Stewart WF, Lipton RB. Acute migraine medications and evolution from episodic to chronic migraine: a longitudinal populationbased study. Headache 2008;48(8):1157-1168

84. Bigal ME, Lipton RB. Excessive acute migraine medication use and migraine progression. Neurology 2008;71(22):18211828

85. Diener HC, Limmroth V. Medication-overuse headache: a worldwide problem. Lancet Neurol 2004;3(8):475-483

86. Lance F, Parkes C, Wilkinson M. Does analgesic abuse cause headaches de novo? Headache 1988;28(1):61-62
87. Ayzenberg I, Obermann M, Nyhuis P, et al. Central sensitization of the trigeminal and somatic nociceptive systems in medication overuse headache mainly involves cerebral supraspinal structures. Cephalalgia 2006;26(9): 1106-1114

88. Fumal A, Laureys S, Di Clemente L, et al. Orbitofrontal cortex involvement in chronic analgesic-overuse headache evolving from episodic migraine. Brain 2006;129(Pt 2):543550

89. Boes CJ, Black DF, Dodick DW. Pathophysiology and management of transformed migraine and medication overuse headache. Semin Neurol 2006;26(2):232-241

90. Saper JR, Hamel RL, Lake AE III. Medication overuse headache $(\mathrm{MOH})$ is a biobehavioural disorder. Cephalalgia 2005;25(7):545-546

91. Fuh JL, Wang SJ, Lu SR, Juang KD. Does medication overuse headache represent a behavior of dependence? Pain 2005;119(1-3):49-55

92. Zeeberg P, Olesen J, Jensen R. Discontinuation of medication overuse in headache patients: recovery of therapeutic responsiveness. Cephalalgia 2006;26(10):11921198

93. Rossi P, Di Lorenzo C, Faroni J, Cesarino F, Nappi G. Advice alone vs. structured detoxification programmes for medication overuse headache: a prospective, randomized, open-label trial in transformed migraine patients with low medical needs. Cephalalgia 2006;26(9):1097-1105

94. Obermann M, Katsarava Z. Management of medicationoveruse headache. Expert Rev Neurother 2007;7(9): $1145-1155$

95. Bøe MG, Mygland A, Salvesen R. Prednisolone does not reduce withdrawal headache: a randomized, double-blind study. Neurology 2007;69(1):26-31

96. Diener HC. How to treat medication-overuse headache: prednisolone or no prednisolone? Neurology 2007;69(1): 14-15

97. Mathew NT. Amelioration of ergotamine withdrawal symptoms with naproxen. Headache 1987;27(3):130-133

98. Krymchantowski AV, Barbosa JS. Prednisone as initial treatment of analgesic-induced daily headache. Cephalalgia 2000;20(2):107-113

99. Lu SR, Fuh JL, Juang KD, Wang SJ. Repetitive intravenous prochlorperazine treatment of patients with refractory chronic daily headache. Headache 2000;40(9): $724-729$

100. Silberstein SD, Schulman EA, Hopkins MM. Repetitive intravenous DHE in the treatment of refractory headache. Headache 1990;30(6):334-339

101. Ford RG, Ford KT. Continuous intravenous dihydroergotamine in the treatment of intractable headache. Headache 1997;37(3):129-136

102. Schwartz TH, Karpitskiy VV, Sohn RS. Intravenous valproate sodium in the treatment of daily headache. Headache 2002;42(6):519-522

103. Katsarava Z, Jensen R. Medication-overuse headache: where are we now? Curr Opin Neurol 2007;20(3):326-330

104. Katsarava Z, Muessig M, Dzagnidze A, Fritsche G, Diener HC, Limmroth V. Medication overuse headache: rates and predictors for relapse in a 4-year prospective study. Cephalalgia 2005;25(1):12-15

105. Garza I, Swanson JW. Answers to frequently asked questions about migraine. Mayo Clin Proc 2006;81(10):1387-1391, quiz 1392 
106. Rozen TD. New daily persistent headache. Curr Pain Headache Rep 2003;7(3):218-223

107. Vanast WJ. New daily persistent headaches definition of a benign syndrome. Headache 1986;26:317-320 (Abstract)

108. Takase Y, Nakano M, Tatsumi C, Matsuyama T. Clinical features, effectiveness of drug-based treatment, and prognosis of new daily persistent headache (NDPH): 30 cases in Japan. Cephalalgia 2004;24(11):955-959

109. Li D, Rozen TD. The clinical characteristics of new daily persistent headache. Cephalalgia 2002;22(1):66-69

110. Bigal ME, Sheftell FD, Rapoport AM, Lipton RB, Tepper SJ. Chronic daily headache in a tertiary care population: correlation between the International Headache Society diagnostic criteria and proposed revisions of criteria for chronic daily headache. Cephalalgia 2002;22(6):432-438

111. Diaz-Mitoma F, Vanast WJ, Tyrrell DL. Increased frequency of Epstein-Barr virus excretion in patients with new daily persistent headaches. Lancet 1987;1(8530):411415

112. Hamada T, Ohshima K, Ide Y, Sakato S, Takamori M. A case of new daily persistent headache with elevated antibodies to Epstein-Barr virus. Jpn J Med 1991;30(2):161-163

113. Meineri P, Torre E, Rota E, Grasso E. New daily persistent headache: clinical and serological characteristics in a retrospective study. Neurol Sci 2004;25(Suppl 3):S281-S282

114. Santoni JR, Santoni-Williams CJ. Headache and painful lymphadenopathy in extracranial or systemic infection: etiology of new daily persistent headaches. Intern Med 1993;32(7):530-532

115. Rozen TD. New daily persistent headache. In: Goadsby PJ, Dodick DW, eds. Chronic Daily Headache for Clinicians. 1st Ed. Hamilton, Ontario: BC Decker Inc.; 2005:209-215

116. Goadsby PJ, Boes C. New daily persistent headache. J Neurol Neurosurg Psychiatry 2002;72(Suppl 2):ii6-ii9

117. Rossi P, Faroni J, Tassorelli C, Nappi G. Diagnostic delay and suboptimal management in a referral population with hemicrania continua. Headache 2009;49(2):227-234

118. Peres MF, Silberstein SD, Nahmias S, et al. Hemicrania continua is not that rare. Neurology 2001;57(6):948-951

119. Dodick D. Hemicrania continua: diagnostic criteria and nosologic status. Cephalalgia 2001;21(9):869-872

120. Matharu MS, Cohen AS, McGonigle DJ, Ward N, Frackowiak RS, Goadsby PJ. Posterior hypothalamic and brainstem activation in hemicrania continua. Headache 2004;44(8):747-761

121. Irimia $\mathrm{P}$, Arbizu J, Prieto $\mathrm{E}$, Fernández-Torrón $\mathrm{R}$, Martínez-Vila E. Activation of the brainstem but not of the hypothalamus in hemicrania continua without autonomic symptoms. Cephalalgia 2009;29(9):974-979

122. Matharu MS, Boes CJ, Goadsby PJ. Management of trigeminal autonomic cephalgias and hemicrania continua. Drugs 2003;63(16):1637-1677
123. Marmura MJ, Silberstein SD, Gupta M. Hemicrania continua: who responds to indomethacin? Cephalalgia 2009; 29(3):300-307

124. Bigal ME, Tepper SJ, Rapoport AM, Sheftell FD. Hemicrania continua: comparison between two different classification systems. Cephalalgia 2002;22(3):242-245

125. Eross EJ, Swanson JW, Dodick DW. Hemicrania continua: an indomethacin-responsive case with an underlying malignant etiology. Headache 2002;42(6):527-529

126. Antonaci F, Sjaastad O. Hemicrania continua: a possible symptomatic case, due to mesenchymal tumor. Funct Neurol 1992;7(6):471-474

127. Valença MM, Andrade-Valença LP, da Silva WF, Dodick DW. Hemicrania continua secondary to an ipsilateral brainstem lesion. Headache 2007;47(3):438-441

128. Rogalewski A, Evers S. Symptomatic hemicrania continua after internal carotid artery dissection. Headache 2005;45(2): 167-169

129. Peres MF, Zukerman E, Porto PP, Brandt RA. Headaches and pineal cyst: a (more than) coincidental relationship? Headache 2004;44(9):929-930

130. Levy MJ, Matharu MS, Meeran K, Powell M, Goadsby PJ. The clinical characteristics of headache in patients with pituitary tumours. Brain 2005;128(Pt 8):1921-1930

131. Pareja J, Sjaastad O. Chronic paroxysmal hemicrania and hemicrania continua. Interval between indomethacin administration and response. Headache 1996;36(1):20-23

132. Pareja JA, Caminero AB, Franco E, Casado JL, Pascual J, Sánchez del Río M. Dose, efficacy and tolerability of longterm indomethacin treatment of chronic paroxysmal hemicrania and hemicrania continua. Cephalalgia 2001;21(9):906910

133. Rozen TD. Melatonin responsive hemicrania continua. Headache 2006;46(7):1203-1204

134. Peres MF, Silberstein SD. Hemicrania continua responds to cyclooxygenase-2 inhibitors. Headache 2002;42(6):530-531

135. Schwedt TJ, Dodick DW, Hentz J, Trentman TL, Zimmerman RS. Occipital nerve stimulation for chronic headache-long-term safety and efficacy. Cephalalgia 2007;27(2):153-157

136. Camarda C, Camarda R, Monastero R. Chronic paroxysmal hemicrania and hemicrania continua responding to topiramate: two case reports. Clin Neurol Neurosurg 2008; 110(1):88-91

137. Burns B, Watkins L, Goadsby PJ. Treatment of hemicrania continua by occipital nerve stimulation with a bion device: long-term follow-up of a crossover study. Lancet Neurol 2008;7(11):1001-1012

138. Garza I, Cutrer F. Pain relief and persistence of dysantonomic features in a patient with hemicrania continua responsive to botulinum toxin type A. Cephalalgia 2009; June 10 (Epub ahead of print) 